\title{
AN ADAPTIVE DIRECTIONAL OVER - CURRENT PROTECTION AND EARTH FAULT PROTECTION OF DISTRIBUTED SYSTEMS
}

\author{
R. Mahendran ${ }^{1}$, D. Deepak ${ }^{2}$ and D. Breeni ${ }^{3}$
}

Abstract-A significant increase in the penetration of distributed generation has resulted in a possibility of operating distribution systems with distributed generation in islanded mode. Using local information, to overcome the challenges of the directional overcurrent protection in distribution systems with distributed generation by use of adaptive protection. The trip characteristics of the relays are updated by detecting the operating states (grid connected or island) and the faulted section. The project also proposes faulted section detection using time overcurrent characteristics of the protective relays. Earth Fault Protection is also done by creating very low Impedance path.

Keywords: Adaptive Protection, Earth fault Relay, Directional overcurrent protection, Distributed Generation.

\section{INTRODUCTION}

The interest of renewed in distributed generation (DG) has resulted in significant penetration of DGs in many distribution systems worldwide. One of the major advantages of higher DG penetration is the possibility of operating the distribution system in an islanded mode. Islanding is a situation in where distribution system becomes electrically isolated from the rest of the power system, due to a fault upstream or any disturbance, yet continues to be energized by the DGs connected with it. It also improves the quality of supply indices and increases the reliability of the system. The distribution system which is in Denmark is characterized by a significant penetration of wind turbine generators (WTGs) and combined heat and power (CHP) plants. If allowed, they can take advantage of the high DG penetration and operate in island mode so as to increase the reliability of the power supply. However, there are various issues which must be resolved before islanding can be realized. One of the main issues is the protection system coordination.

The fault current depends on the sources of the short circuit power. The transmission grid generally has higher short circuit power compared to a small DG connected to distribution system. Therefore, when a distribution system is islanded, the fault current seen by protection relays is less than the fault cur-rent seen when the distribution system is connected to the trans-mission grid. Bolted three-phase faults at the end of each line are simulated for the test distribution system. There is a significant difference in the fault currents for these two conditions.

An overcurrent protection system designed to operate in grid-connected mode may take longer time to clear the faults when the distribution system is islanded. Electrical equipment (e.g., motors connected at low voltage levels) is equipped with protection system that may disconnect them when the voltage goes lower than a set value for a certain period of time. This may also apply to power sources like wind turbine generators, which are becoming common in many distribution systems. Thus, by not clearing the fault faster, not only loads but also some generations might be

\footnotetext{
${ }^{1}$ Assistant Professor, Department of EEE, S.A Engineering College, Chennai.

${ }^{2}$ UG Scholar: Department of EEE, S.A Engineering College, Chennai.

${ }^{3}$ UG Scholar: Department of EEE, S.A Engineering College, Chennai.
} 
lost, which is undesirable. On the other hand, the protection system can be designed to clear faults during island operation at lower short circuit power. But it also runs into a problem when the distribution system is connected to the trans-mission grid. Faults may trip the breakers even when it is unnecessary. Furthermore, if some generators are lost after a fault, relays may not see the same amount of fault current as compared to the condition when all the generators are online. Bolted three-phase faults at the beginning of each line are simulated for the test system. There is a difference in fault currents during these two scenarios.

\section{DETAILED STUDY}

To Minimize the Fault Current in the system. The excess power generation from the wind plant will be supplied to the grid. Earth Fault protection. Frequency is maintained within a narrow range in the grid. By using ETAP, ETAP Electrical Transient Analysis Program. Electrical components such as Transformers, Transmission Line, Motors, Generators can be Modelled. Designing and Calculation are made easy. Easier to design components than EMTP RV. SLD is made to support EMTP directly.

A flywheel storage unit is used to increase the short-circuit power of the microgrid to make the fault detection possible from traditional relays. Storage requires large investment and does not guarantee that faults are cleared on time unless they match the short circuit power of transmission grid. A single setting (for island condition) is used for relays and the distribution system is islanded when there is a fault within the distribution system. Although, the proposed methodology is simple, it will frequently island the system and thus is not desirable particularly when the total load is larger than the total generation in the distribution system. A delay has been introduced to clear faults in the microgrid but this also runs into problems similar to those as described earlier. Therefore an adaptive overcurrent protection scheme is required, which will use different sets of overcurrent protection set-points for different conditions.

\section{ADAPTIVE PROTECTION RELAY}

Adaptive protection is normally "an online activity which modifies the protective response to a complete change in the system requirements in a timely manner by controlling of externally generated signals or by controlled action". Thus Adaptive protection of a distribution system can be realized with the use of microprocessor-based directional overcurrent relays (DOCR).

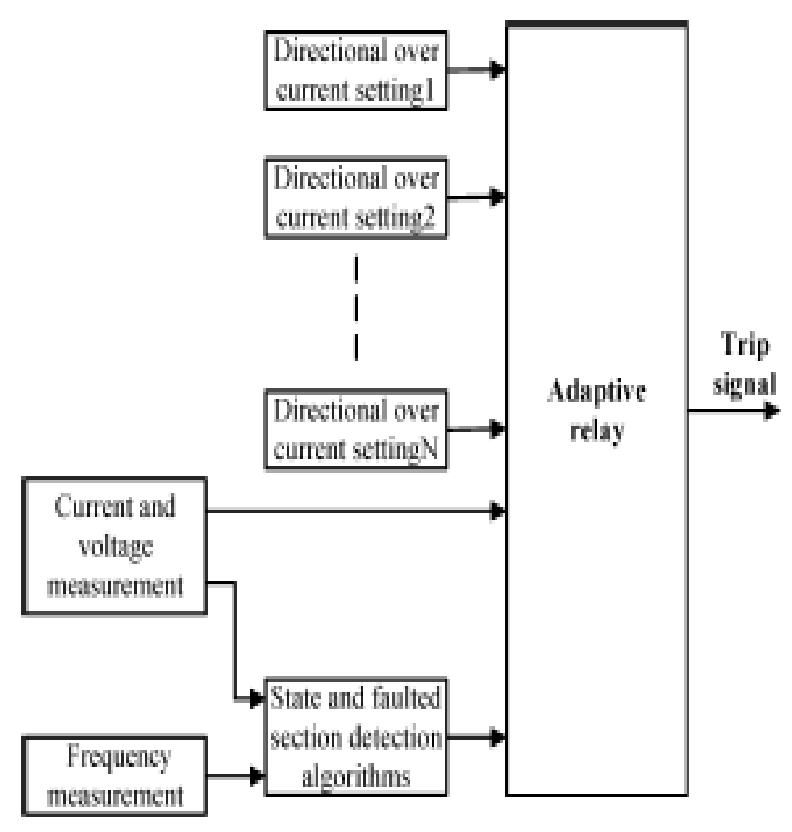

Figure 1: Block Diagram of Adaptive Protection Relay 
DOCR have the possibility to choose different tripping characteristics. Modern digital overcurrent relays for low voltage applications have 2-4 settings groups. Settings may be changed by using communication. But, implementing a communication system between the relays is complex and may require high cost and may not be economical for small distribution systems. Therefore, this paper proposes a simple adaptive overcurrent protection, which chooses relay tripping characteristics is based only on the change in system conditions (island or grid condition) or loss of some generators using only local information. One of the advantages of using local information only is that any problem with a relay will be confined within the relay only.. For a solidly grounded system, fault currents are similar for all types of faults. For the ungrounded or resonant grounded systems, negative sequence or zero sequence currents is used to detect unsymmetrical faults. However, in the paper the studies are limited to only the positive sequence. The fault type in this paper is therefore it is limited to three-phase fault.

\section{IV.DIRECTIONAL OVERCURRENT RELAY}

Directional Over - Current Protection comprises of Over-Current Relay and Power Directional Relay on a Single Relay Casing. If Power Flow is in opposite direction, the Directional Overcurrent Protection remains un-operative. The directional relay recognizes the direction in which fault occurs, relative to the location of the relay. The circuit breaker will be provided with directional Relay which will trip the breaker if fault power flow is in same direction alone. Ref. Fig 2.

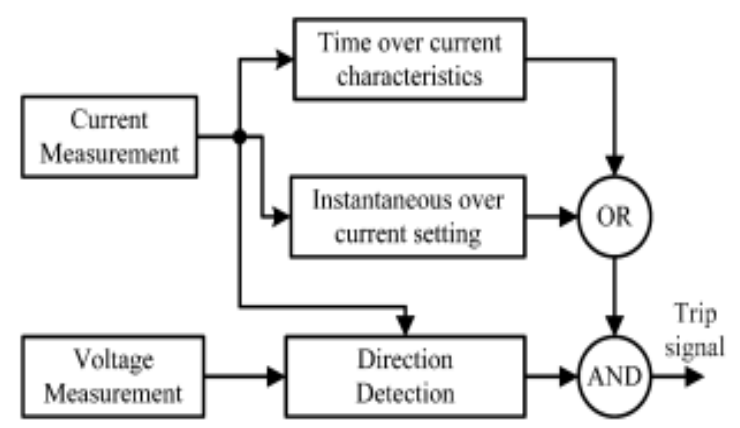

Figure 2: Block Diagram of Directional Overcurrent Relay

\section{EARTH FAULT RELAY}

It is a Relay used in the power system to Detect Neutral or Ground Faults measure the difference of Three Phase Power. Earth Fault Protection requires a Current Transformer to Sense an imbalance in a three-phase circuit. Directional earth fault relays sense the direction in which earth fault occurs with respect to relay location and it operates for fault in a particular direction.

\section{PROPOSED METHODLOGY}

As mentioned earlier, there is a significant change in fault power when the distribution system is islanded from the trans-mission grid compared to a situation when it is still connected to it. The adaptive relay detects the status (grid connected or island) of the system, by using state detection algorithms and selects the tripping characteristics accordingly. The flow chart for the adaptive protection where the relays choose the appropriate trip characteristics is shown in Fig. 2. An islanding detection technique based on average rate of voltage change is presented in. The adaptive relays use the islanding detection technique that is based on appropriate technique might be used instead. Transmission grid generally maintains frequency within a narrow range. Frequency is maintained within the range of 49.9-50.1 Hz in the Union for the Coordination of Transmission of Electricity (UCTE) system. Therefore, change in DG's active power will have a negligible impact on system frequency when the distribution system is connected to transmission grid. On the other hand, the change in active power will drive the frequency outside the range of 49.9-50.1 Hz when the distribution system is islanded. A technique to detect when a distribution system is resynchronized to the transmissions system, based on frequency measurement, is presented in detail. 
A design study can be carried out to set the tripping characteristics (time over current characteristics) of each relay for both a grid connected condition and an island condition. Faults in the distribution system might result in loss of some generators. This changes the short circuit power. Forward relays determine the number of generators lost by identifying the faulted area and triggers the corresponding reverse relays to choose an-other setting. For example, in the test distribution system shown in relay R21 may have two tripping characteristics, one for the case when all generators are online and the other when there is no GTG5 connected to the system. To explain the proposed methodology in a simple way, the adaptive protection is designed to choose from two trip characteristics based on the network configuration. If desired, the methodology can be extended to implement more settings for the relays. Three possible cases are considered.

Case 1 is the normal case when all the DGs are present and the distribution system is connected to the grid.

Case 2 is an island condition where the connection to the transmission grid is lost.

Fig4. \& Fig5. Shows the system in Grid Connected mode and Islanded model respectively, Relays R12, R23, R34, and R45 have two trip characteristics, one for Case 1 and one for Case 2. Similarly, R43, R32, and R21 also have two trip characteristics, one for Case 1 and one for Case 2. R56 and R17 only see forward current when there is a fault in their protection zone and therefore they have only one trip characteristic. The only source of forward current for R71 is the CHP plant. Therefore, R71 has only one trip characteristic. Similarly, the only source of forward current for R54 is GTG5 and therefore it has only one trip characteristic. Fig 5. Shows the system operating in Islanded mode. i.e. Grid will be disconnected from the system and with the help of CHP Plant and WTG (Wind Generators) the system will run by taking power from sec. source. The time dial setting of each relay is designed in such a way that the upstream relay will provide a backup function for the downstream relay. For example, assume that $\mathrm{I}_{4}$ and $\mathrm{I}_{45}$ are the currents seen by relays $\mathrm{R} 34$ and R45, respectively, for a fault in Line56 near Bus5. R56 picks up at $50 \mathrm{~ms}$ (instantaneous pickup) to clear the fault. If it fails, then R45 picks up at $150 \mathrm{~ms}$ for I45. This gives enough time for instantaneous pickup setting of R56 to pickup and the corresponding circuit breaker to open to clear the fault. If both R56 and R45 fail to pickup, then R34 will pickup at $250 \mathrm{~ms}$ for $\mathrm{I} 4$ to clear the fault. Other relays are similarly designed. For R17, relays R21, R32, R43, R54, and R65 will provide the backup function..

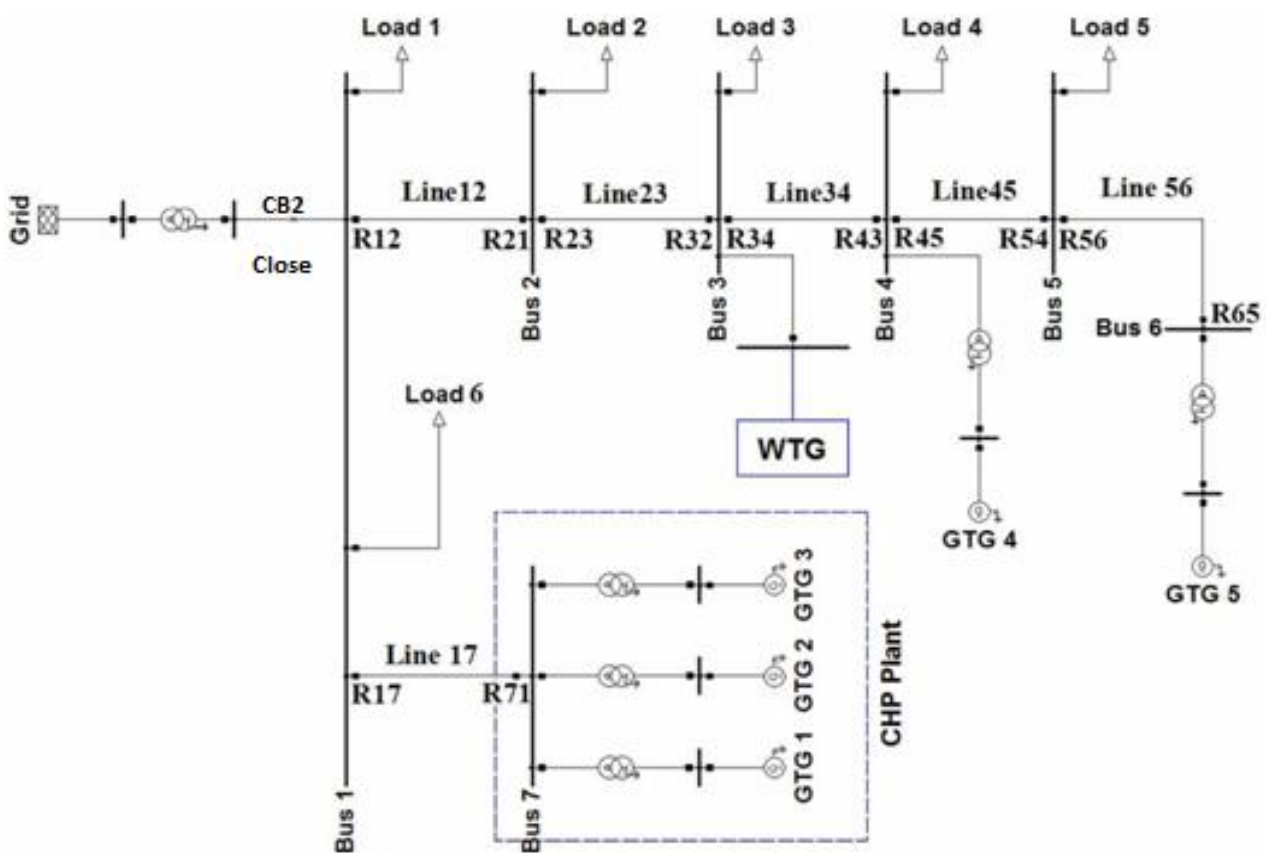

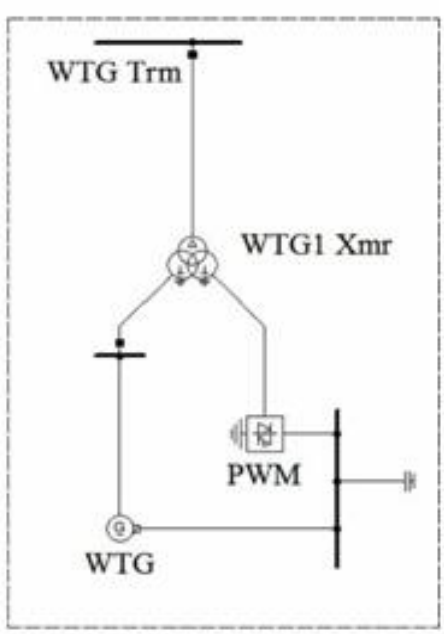

Wind Turbine Generator

Figure 2: Grid Connected Mode 


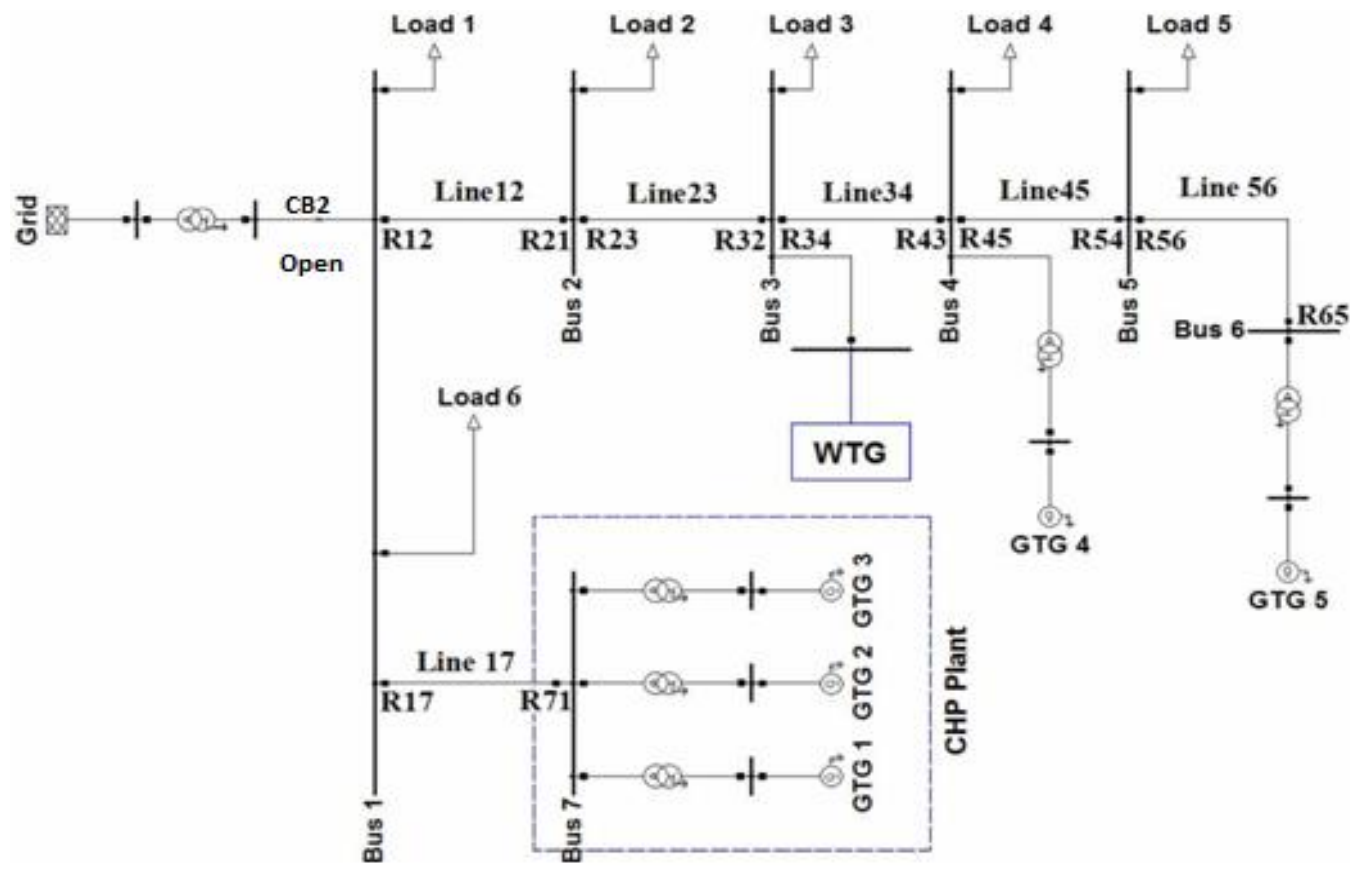

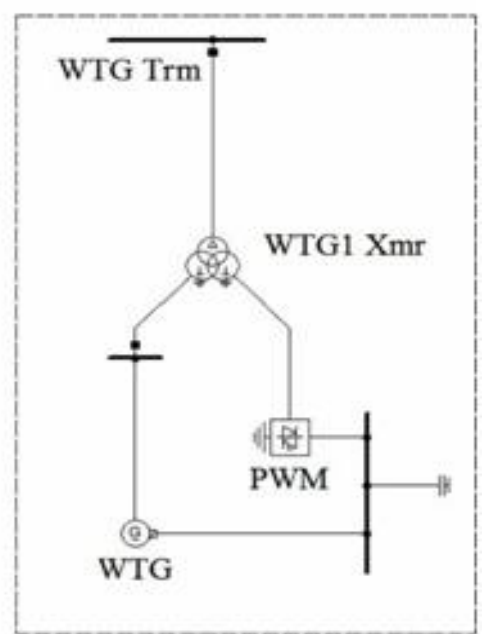

Wind Turbine Generator

Figure 5: Islanded Mode

\section{FLOW CHART}

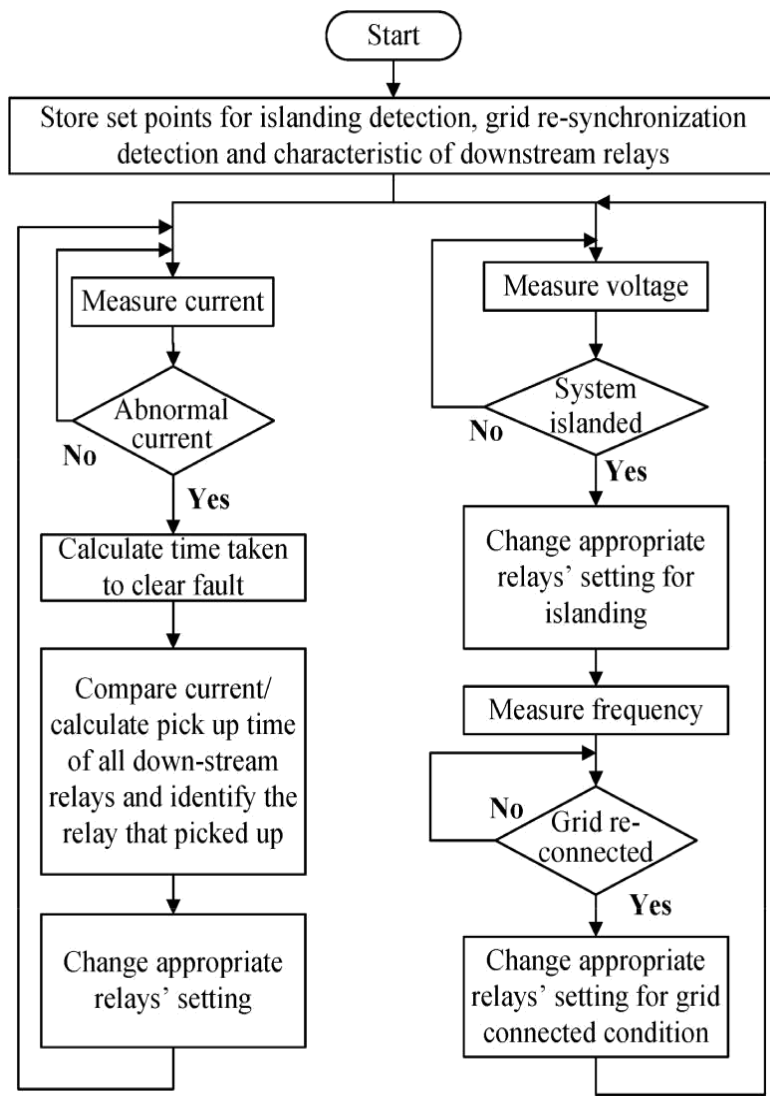

Figure 6: Flow Chart 


\section{SIMULATION RESULTS}

Islanding is simulated by opening the circuit breaker (CB). The relay takes $10 \mathrm{~ms}$ to close its trip contacts and the circuit breaker takes $60 \mathrm{~ms}$ to clear the fault. All the faults are simulated at time $t=0 \mathrm{~s}$. Wind turbines connected to the Danish power system should satisfy the Danish grid code. The fault ride through capability, according to the Danish grid code, is depicted in Fig. 6.1. Based on the grid code, the protection of the wind turbine connected at Bus4 is designed as depicted in Fig. 12, for simplicity. The grey area represents the region where the wind turbine disconnects.

Fig 7 shows the time overcurrent plot for case 1. Where it also shows the relay tripping characteristics. Fig 8 shows the Protection of Wind Turbine where the limit where the wind turbine can be Protected. fig 7 shows the time overcurrent characteristics for case 2.

A three-phase fault with a fault resistance of $0.1 \Omega$ is simulated at the middle of line Line23, at $t=0 \mathrm{~s}$, in Case 2 . The trip characteristics of the reverse relays are the same as the status of the circuit breakers. Since there is no GTG5, the fault current seen by R32 is less compared to Case1 when all DGs are present. It therefore takes a longer time to clear the fault. As a result, the WTG is tripped. The same fault is simulated again but now the trip characteristics for the reverse relays are set as in Fig. 10. Fig. 18 shows the circuit breaker status.

The same fault is simulated again but now the trip characteristics for the reverse relays are set as shows the circuit breaker status. As expected, the fault is cleared by opening of the breakers at the two ends of the line $120 \mathrm{~ms}$ after the fault (due to instantaneous pickup). The WTG stays online due to the quicker fault clearing. The same fault is simulated again. Case 1 is considered but the trip characteristics of the re-verse relays are kept as per status of the circuit breakers' status. Due to the increase in the fault current due to GTG5, R43 also trips along with R23 and R32. This is unnecessary as the fault could have been cleared by opening of breakers corresponding to R23 and R32. Furthermore, the opening of R43 results in increase in Bus3 voltage and tripping of WTG.

Table 1: Grid Connected Mode

\begin{tabular}{lccc}
\hline Relay & $\mathbf{I}_{\mathbf{p}} \mathbf{( A )}$ & $\mathbf{T}_{\mathbf{d}}$ & $\begin{array}{c}\text { Instantaneous } \\
\text { pickup current } \\
\text { (A) }\end{array}$ \\
\hline R5-6 & 130 & 0.026857 & 650 \\
R4-5 & 130 & 0.081934 & 5450 \\
R3-4 & 260 & 0.109484 & 5600 \\
R2-3 & 350 & 0.144592 & 5950 \\
R1-2 & 350 & 0.195207 & 6700 \\
R7-1 & 390 & 0.070048 & 990 \\
R1-7 & 100 & 0.006605 & 250 \\
R2-1 & 350 & 0.010215 & 582 \\
R3-2 & 350 & 0.01723 & 585 \\
R4-3 & 260 & 0.037559 & 566 \\
R5-4 & 130 & 0.04933 & 288 \\
R6-5 & 130 & 0.06055 & 295 \\
\hline
\end{tabular}

Table 1: Islanded Mode

\begin{tabular}{llll}
\hline Relay & $\mathbf{I}_{\mathbf{p}}$ (A) & \multicolumn{1}{c}{$\mathbf{T}_{\mathbf{d}}$} & $\begin{array}{c}\text { Instantaneous } \\
\text { pickup current } \\
\text { (A) }\end{array}$ \\
\hline R5-6 & 130 & 0.026857 & 650 \\
R4-5 & 130 & 0.081934 & 1120 \\
R3-4 & 260 & 0.109484 & 930 \\
R2-3 & 350 & 0.144592 & 960 \\
R1-2 & 350 & 0.195207 & 970 \\
R7-1 & 390 & 0.070048 & 990 \\
R1-7 & 100 & 0.006605 & 250 \\
R2-1 & 175 & 0.006605 & 305 \\
R3-2 & 175 & 0.010215 & 310 \\
R4-3 & 90 & 0.01723 & 284 \\
\hline
\end{tabular}




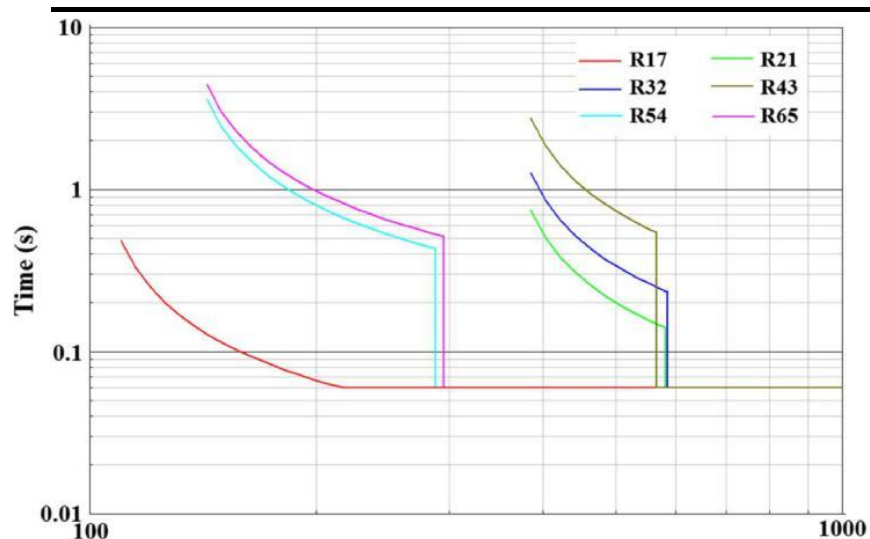

Current in primary of CT (A)

Figure 7. Time Overcurrent Plot for Case 1

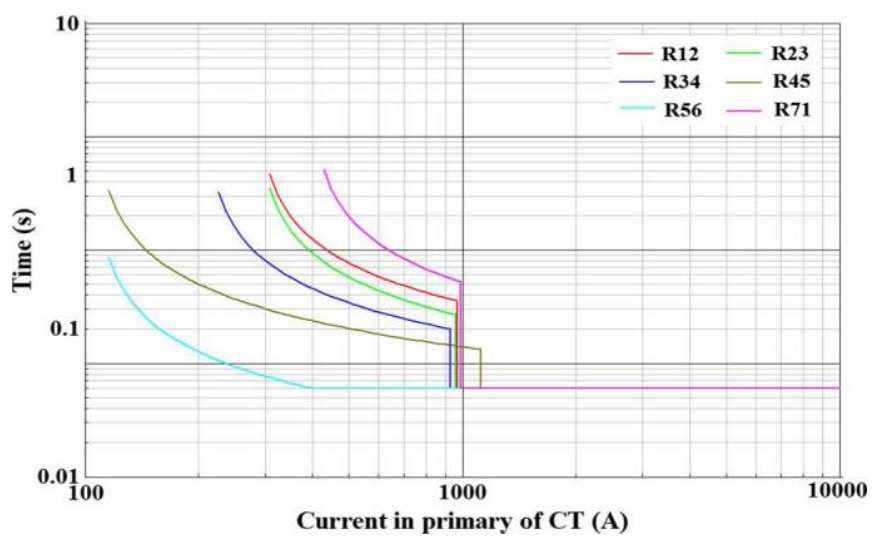

Figure 9. Time Overcurrent Plot for Case 2

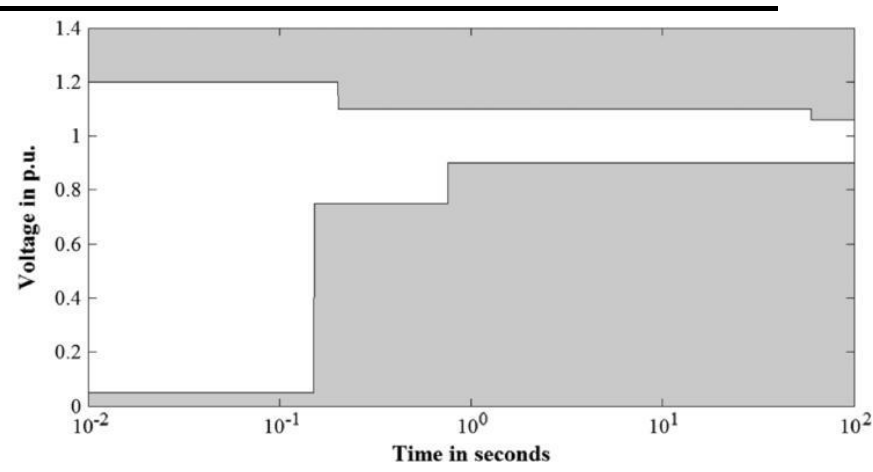

Figure 8. Protection of Wind Turbine

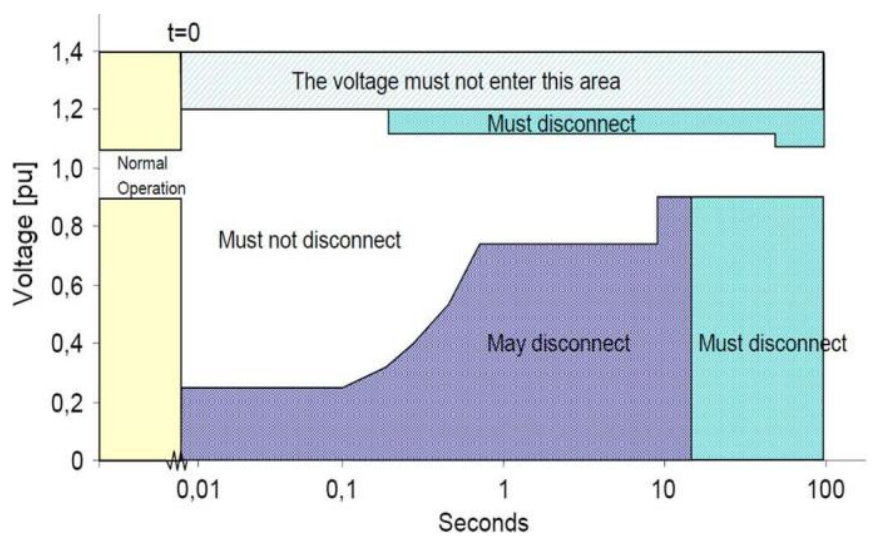

Figure 10. Danish Code

\section{CONCLUSION}

Significant DG penetration in the distribution system world-wide has presented an opportunity to operate distribution sys-tems in an island mode during some disturbances in the grid up-stream to improve the reliability of power supply. But the DG does not contribute as much fault current as the transmission grid. Hence the overcurrent protection system designed for the grid connected condition results in longer fault clearing time when the distribution system is islanded. This might result in loss of some generators and loads. Also, setting the protection system for islanded condition may result in unnecessary operation of some relays. Adaptive protection overcomes this by up-dating the trip characteristics of the relays when the distribution system condition changes (like grid connected, island and losing some generators). The adaptive protection uses only local information to update its setting. State detection algorithms are used to change the setting for grid connected condition to island condition and vice versa. The faulted section is determined by measuring the current and using the time overcurrent characteristics of downstream relays. The relay trip characteristic is updated if any generator is lost. The proposed method assumes that the initial state of the distribution system is known and is valid for loss of generators, islanding and grid reconnection only. When the generators are connected to the distribution system, the set-tings cannot be updated based on local information. The pro-posed faulted section detection may also be used to detect the faulted section and speed up repair work.

The proposed adaptive technique is simple. It uses the state detection algorithms and detection of the faulted section to know the network condition to update the relays trip characteristics to clear the fault sooner and satisfy the protection philosophy. 
An Adaptive Directional Over - Current Protection And Earth Fault Protection Of Distributed Systems 279

\section{REFERENCES}

[1] Optimal coordination of directional overcurrent relays (DOCR) in a ring distribution network with distributed generation (DG) using genetic algorithm Amir Alipour; Michael Pacis 2016 IEEE Region 10 Conference (TENCON).

[2] Detection of direction change in prefault current in current-only directional overcurrent protection Abhisek Ukil IECON 2016 - 42nd Annual Conference of the IEEE Industrial Electronics Society.

[3] Planning the coordination of directional overcurrent relays for distribution systems considering DG. Hatem Zeineldin; Lukasz Huchel 2016 IEEE Power and Energy Society General Meeting (PESGM).

[4] A Simple Adaptive Overcurrent Protection of Distribution Systems With Distributed Generation. Pukar Mahat, Member, IEEE, Zhe Chen, Senior Member, IEEE, Birgitte Bak-Jensen, Member, IEEE, and Claus Leth Bak, Senior Member, IEEE,2011.

[5] Optimum coordination of directional overcurrent relay in presence of distributed generation using genetic algorithm. Sahebrao $V$. Chakor; Tanuja N. Date 2016 10th International Conference on Intelligent Systems and Control (ISCO).

[6] Planning the Coordination of Directional Overcurrent Relays for Distribution Systems Considering DG. Eukasz Huchel; Hatem H. Zeineldin IEEE Transactions on Smart Grid,2016.

[7] Protection Coordination for Microgrids with Grid-Connected and Islanded Capabilities using Dual Setting Directional Overcurrent Relays Hatem M. Zeineldin; Heba H. Sharaf; Ehab El-Saadany IEEE Transactions on Smart Grid 2016.

[8] A protection scheme for optimum coordination of directional overcurrentrelays in presence of distributed generation. Amol A alage; Nitin D Ghawghawe, 2015 International Conference on Electrical, Electronics, Signals, Communication and Optimization (EESCO). 